\title{
SCIENTIFIC REPORTS

\section{Efficacy and Safety of Nivestim Versus Neupogen for Mobilization of Peripheral Blood Stem Cells for Autologous Stem Cell Transplantation}

\author{
Cindy $\mathrm{Chew}^{{ }^{*}}$ \& Hong Yen $\mathrm{Ng}^{2}$
}

A retrospective cohort study was conducted in Singapore General Hospital to study the safety and efficacy of biosimilar granulocyte-colony stimulating factor (G-CSF) Nivestim for chemomobilization of stem cells for autologous stem cell transplant (autoSCT). All patients who underwent an autoSCT between January 2011 and December 2016 were screened for eligibility. A total of 194 patients were screened, and 131 were included. Nivestim was used in 65 patients and the originator G-CSF (Neupogen) in 66. Patient characteristics were similar between both arms except for chemomobilization regimen used $(p<0.0001)$. Mobilization success rates were found to be comparable, at $96.9 \%$ (Nivestim) and $97 \%$ (Neupogen). Adverse events rates were also similar. Median duration of G-CSF use and hospitalization were both found to be shorter in the Nivestim arm. Median drug acquisition cost per mobilization cycle was significantly lower in the Nivestim arm at $\$ 533.40$ (range $\$ 213.40-\$ 1280.20$ ) as compared to $\$ 1261.90$ (range $\$ 574-\$ 2755.20)$ in the Neupogen arm $(p<0.0001$ ). No difference was observed for neutrophil and platelet engraftment after autoSCT. Nivestim was found to be safe and non-inferior to Neupogen for chemo-mobilization of stem cells for autoSCT, and associated with lower cost and shorter length of hospitalization.

Autologous stem cell transplantation (autoSCT) is an important treatment modality in the management of various chemo-sensitive malignant conditions including multiple myeloma, Hodgkin's and non-Hodgkin's lymphoma, soft tissue sarcoma, germ cell cancer and Ewing sarcoma ${ }^{1,2}$. In the management of multiple myeloma, autoSCT is currently the standard of care, even in this era of novel agents ${ }^{3}$. A recent meta-analysis conducted by Dhakal et al. demonstrated superior progression free survival with autoSCT even with the use of novel agents during induction therapy ${ }^{4}$. In the setting of relapsed lymphoma, autoSCT can offer as an alternative management option if patients failed systemic treatment. The National Comprehensive Cancer Network (NCCN) guidelines have listed autoSCT as standard of care for lymphoma patients in second remission ${ }^{5,6}$. The Parma study demonstrated that salvage chemotherapy followed by autoSCT yielded a superior 5-year event free survival when compared to salvage chemotherapy alone in patients with relapsed lymphoma ${ }^{7}$.

Mobilization of peripheral blood stem cells (PBSCs) upon achieving remission after induction chemotherapy constitutes a critical component in the continuum of an autoSCT. These PBSCs are then frozen and stored for reinfusion into the patient as a form of "rescue" after administering high dose chemotherapy, constituting an autoSCT. Recombinant granulocyte colony-stimulating factor (G-CSF) plays a pivotal role in ensuring success of an autoSCT. It is required to mobilize stem cells from the bone marrow into the peripheral blood to allow for harvesting via apheresis. Chemotherapy may be employed to facilitate the process of mobilization by causing a rebound production of stem cells in the bone marrow for harvesting (chemo-mobilization). Besides, G-CSF is also essential in accelerating hematopoietic recovery after autoSCT ${ }^{8-10}$.

\footnotetext{
${ }^{1}$ Department of Pharmacy, National Cancer Centre, Singapore, 11 Hospital Crescent, 169610, Singapore. ${ }^{2}$ Department of Pharmacy, Singapore General Hospital, Block 7 Level 2, Outram Road, 169608, Singapore. *email: cindy.chew.y.x@nccs.com.sg
} 
With the recent expiry of patent for Neupogen, many biosimilar G-CSFs have been developed and made available. A biosimilar is a biological agent that is comparable in terms of quality, safety and efficacy to the approved original biological medicine $e^{11,12}$. These biosimilars were developed with the intent of reducing cost as compared to the originator, translating to more affordable healthcare. The manufacturing processes of these biosimilars were independent of the proprietary methods. Hence, the quality, purity and clinical activity of biosimilars may be of concern ${ }^{11}$.

Biosimilar G-CSFs have been shown to exhibit bioequivalence to Neupogen in terms of pharmacokinetics and pharmacodynamics properties ${ }^{8,13,14}$. In a meta-analysis of three large randomized, two-arm study for the management of chemotherapy-related neutropenia in non-Hodgkin's lymphoma, breast and lung cancers, biosimilar G-CSFs were found to be comparable to Neupogen ${ }^{9}$. Based on the available data, biosimilar G-CSFs were approved by the European Medicines Agency (EMA) in 2010 for the same indications as Neupogen based on comparable efficacy, quality and safety ${ }^{10,15}$. However, the long term safety data as well as effects on quality of PBSCs are still lacking.

In April 2014, a biosimilar G-CSF, Nivestim was introduced into Singapore General Hospital (SGH) to be used in place of Neupogen, with the exception of mobilization of PBSCs for allogeneic stem cell transplant due to the unknown long-term effect on healthy donors. While biosimilar G-CSFs are approved for mobilization of PBSCs for autologous HSCT, majority of the studies examining the efficacy and safety in this setting involved biosimilar, Zarzio. There were concerns whether the different manufacturing processes will result in micro-heterogeneity among the biosimilars, affecting the mobilization process and quality of PBSCs mobilized for transplant ${ }^{8}$. With limited evidence on the effect of Nivestim for mobilization of stem cells and resultant recovery from an autoSCT, this study aimed to compare the efficacy and safety of biosimilar G-CSF (Nivestim) with originator G-CSF (Neupogen) in the context of chemo-mobilization.

\section{Method}

Study design. This was a single center, retrospective cohort study conducted at SGH, comparing the efficacy and safety of biosimilar G-CSF (Nivestim) with originator G-CSF (Neupogen) in chemo-mobilization of PBSCs for autoSCT. This study was approved by Singhealth Centralized Institutional Review Board (CIRB Ref 2016/2233) with waiver of informed consent.

All patients who underwent autoSCT in SGH from January 2011 to November 2016 were screened for eligibility. Patients who underwent autoSCT from January 2011 to March 2014 received Neupogen for mobilization while the others received Nivestim due to change in the hospital drug formulary in April 2014.

Study participants. Inclusion criteria included at least 18 years of age; diagnosis of multiple myeloma, lymphoma or leukemia; and underwent first chemo-mobilization for autoSCT. Patients were excluded if they were diagnosed with any other autoimmune or hematological disease apart from the above-mentioned conditions; previously failed mobilization; received both plerixafor and G-CSF, or Pegylated G-CSF for mobilization; or had prior transplant.

Sample size calculation. Sample size was calculated using an $80 \%$ power and a two-sided $\alpha=5 \%$ to detect a non-inferiority of $20 \%$ between Neupogen and Nivestim. This yielded a sample size of 65 patients per arm.

Outcomes. The primary outcome was the proportion of mobilization success, defined as a harvest of at least $2 \times 10^{6} \mathrm{CD} 34^{+}$cells per kilogram body weight. Secondary outcomes included incidence and severity of adverse events, total number of cells mobilized, duration of injections received per mobilization, number of G-CSF injections received, number of days of apheresis required, length of hospitalization for mobilization, drug acquisition cost of G-CSF, and time to engraftment of neutrophil and platelet after subsequent autoSCT. Severity of adverse events was graded based on Common Terminology Criteria for Adverse Events (CTCAE) version 4.03. Length of hospitalization for mobilization was calculated from the day of admission for planned PBSCs mobilization to discharge after completion of harvest. Time to engraftment of neutrophil and platelet was defined as the time taken for engraftment to take place after high dose chemotherapy and infusion of PBSCs. Neutrophil engraftment was defined as the first of the 3 consecutive days, on which the absolute neutrophil count (ANC) was $0.5 \times 10^{9} / \mathrm{L}$ or greater, while platelet engraftment was defined as first of 3 consecutive days, on which the platelet count was $20 \times 10^{9} /$ L or greater without platelet transfusion in the preceding 7 days ${ }^{16,17}$.

Statistical analysis. Categorical data including proportion of mobilization success and adverse events in both arms were compared using chi-square test. Continuous variables such as number of cells mobilized, duration and number of G-CSFs received, number of days of apheresis, length of hospitalization, and time to engraftment of neutrophil and platelet between the two arms were compared using Mann-Whitney U test. Binary logistic regression was performed to investigate potential confounding effects of parameters that were significantly different between the two arms at baseline. All other outcomes were reported using descriptive statistics. All statistical analyses were performed using IBM SPSS software version 24 and Microsoft Excel 2013.

\section{Results}

Patient demographics. A total of 194 patients who underwent autologous stem cell transplant from January 2011 to November 2016 were screened for inclusion. Among these, 63 patients were excluded due to various reasons as shown in Fig. 1. Of the patients included, 65 received Nivestim and 66 received Neupogen. Majority of the patients had multiple myeloma $(\mathrm{n}=79)$, and were in complete remission or partial remission at transplant $(\mathrm{n}=85)$. As shown in Table 1, baseline demographics were similar in both arms with the exception of the type of chemo-mobilization regimen used. 


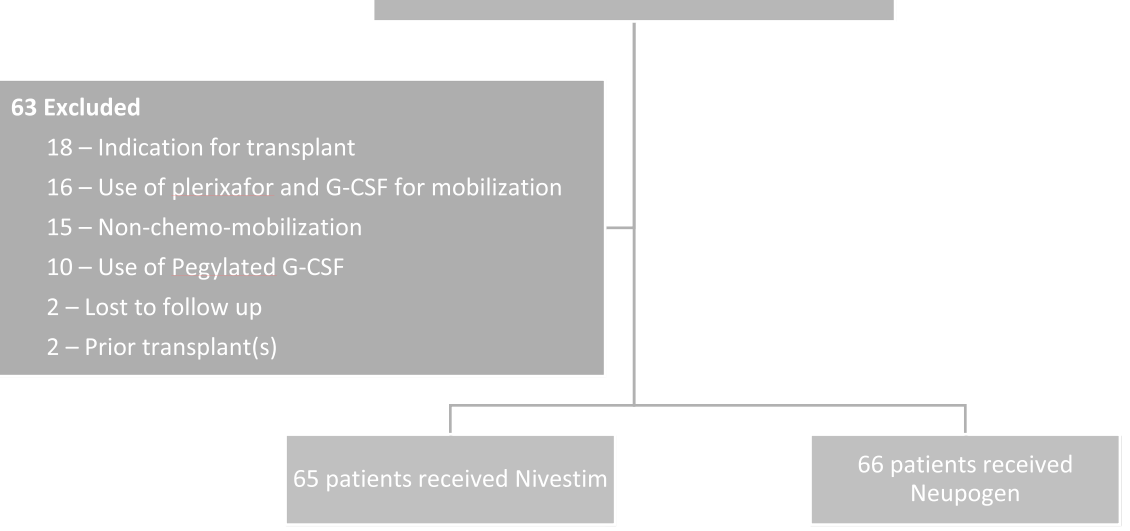

Figure 1. Patient recruitment.

\begin{tabular}{|l|l|l|l|}
\hline & $\begin{array}{l}\text { Nivestim } \\
(\mathbf{N}=\mathbf{6 5})\end{array}$ & $\begin{array}{l}\text { Neupogen } \\
(\mathbf{N}=66)\end{array}$ & p-value \\
\hline Gender, n (\%) & & & 0.183 \\
\hline • Male & $38(58.5)$ & $41(62.1)$ & \\
\hline Median age (years) & 57 & 56 & 0.142 \\
\hline Range & $20-71$ & $18-73$ & \\
\hline Diagnosis, n (\%) & & & 0.064 \\
\hline$\bullet$ Multiple Myeloma & $34(52.3)$ & $45(68.2)$ & \\
\hline$\bullet$ Lymphoma & $31(47.7)$ & $21(31.8)$ & \\
\hline Median weight (kg) & 59.1 & 65 & 0.218 \\
\hline Range & $39-94.7$ & $38.2-138$ & \\
\hline Disease status, n (\%) & & & 0.886 \\
\hline$\bullet$ Complete remission & $29(44.6)$ & $33(50)$ & \\
\hline$\bullet$ Partial response & $10(15.4)$ & $13(19.7)$ & \\
\hline$\bullet$ Progression & $1(1.5)$ & $1(1.5)$ & \\
\hline$\bullet$ Relapse & $25(38.5)$ & $19(28.8)$ & \\
\hline $\begin{array}{l}\text { Number of lines of treatment prior to } \\
\text { mobilization, n (\%) }\end{array}$ & & & 0.936 \\
\hline$\bullet 1$ & $39(60)$ & $43(65.2)$ & \\
\hline$\bullet 2$ & $24(36.9)$ & $17(25.7)$ & \\
\hline$\bullet \geq 3$ & $2(3.1)$ & $6(9.1)$ & \\
\hline Chemo-mobilization regimen, n (\%) & & & $<0.0001$ \\
\hline$\bullet$ Cyclophosphamide/vinorelbine & $27(41.5)$ & $22(33.3)$ & \\
\hline$\bullet$ High dose cyclophosphamide & $6(9.2)$ & $25(37.9)$ & \\
\hline$\bullet$ Others & $32(49.2)$ & $19(28.8)$ & \\
\hline & & & \\
\hline
\end{tabular}

Table 1. Patient Demographics.

Mobilization success. Mobilization success was found to be similar, observed in 63 patients (96.9\%) in the Nivestim arm as compared to 64 patients $(97 \%)$ in the Neupogen arm $(\mathrm{p}=0.988)$, as shown in Table 2. Following mobilization and harvesting, a higher number of patients proceeded on to autoSCT in the Nivestim $\operatorname{arm}(\mathrm{n}=56$, $86.2 \%)$ as compared to the Neupogen arm $(n=49,74.3 \%)$. Majority of the patients who did not proceed to receive autologous stem cell transplant were due to disease relapse, complications, or expired before transplant. However, this difference did not reach statistical significance.

Across both arms, majority of the patients received either cyclophosphamide $1.5 \mathrm{~g} / \mathrm{m}^{2} /$ vinorelbine $25 \mathrm{mg} / \mathrm{m}^{2}$ or single agent cyclophosphamide $4 \mathrm{~g} / \mathrm{m}^{2}$ as chemo-mobilization regimen. Though the type of chemo-mobilization regimen used was significantly different between the two arms at baseline, analysis via logistic regression did not identify this as a potential confounder to our results. Sub-group analysis based on chemo-mobilization regimen yielded comparable success rate using either cyclophosphamide/vinorelbine or high dose cyclophosphamide regimen (Table 3). Similarly, sub-group analysis based on prior treatment lines did not reveal any statistical difference in mobilization success rates between patients with only one line of prior treatment and those who were more heavily pre-treated. 


\begin{tabular}{|c|c|c|c|}
\hline & Nivestim $(\mathrm{N}=65)$ & Neupogen $(\mathrm{N}=66)$ & p-value \\
\hline \multicolumn{4}{|l|}{ Primary Outcome } \\
\hline - Mobilization success, n (\%) & $63(96.9)$ & $64(97)$ & 0.988 \\
\hline \multicolumn{4}{|l|}{ Secondary Outcomes } \\
\hline \multicolumn{4}{|l|}{ Safety } \\
\hline - Incidence of adverse events, n (\%) & $12(18.5)$ & $5(7.6)$ & 0.583 \\
\hline Back pain & 6* & 4 & \\
\hline Bone pain & 3* & 1 & \\
\hline Body aches & 2 & 0 & \\
\hline Headaches & 1 & 0 & \\
\hline Hip pain & 1 & 0 & \\
\hline Atypical chest pain & 1 & 0 & \\
\hline - Missing data, n (\%) & $25(38.5)$ & $51(77.3)$ & \\
\hline \multicolumn{4}{|l|}{ Mobilization and Apheresis } \\
\hline - Median number of cells mobilized $\left(\mathrm{x} 10^{6}\right)$ & 7.56 & 6.81 & 0.318 \\
\hline Range & $0-45.9$ & $0.2-40.63$ & \\
\hline $\begin{array}{l}\text { - Median duration of G-CSF received per } \\
\text { mobilization (days) }\end{array}$ & 9 & 10 & 0.126 \\
\hline Range & $3-18$ & $5-24$ & \\
\hline $\begin{array}{l}\text { - Median number of Injections received } \\
\text { per mobilization }\end{array}$ & 20 & 22 & 0.49 \\
\hline Range & $8-48$ & $10-48$ & \\
\hline $\begin{array}{l}\text { - Median number of apheresis sessions } \\
\text { (days) }\end{array}$ & 2 & 2 & 0.874 \\
\hline Range & $0-4$ & $1-7$ & \\
\hline - Medium length of hospitalization (days) & 15 & 17 & 0.035 \\
\hline Range & $2-152$ & $5-61$ & \\
\hline \multicolumn{4}{|l|}{ Drug Acquisition Cost $^{\dagger}$} \\
\hline $\begin{array}{l}\text { - Median drug acquisition cost for G-CSF } \\
\text { per patient (\$) }\end{array}$ & 533.4 & 1261.9 & $<0.0001$ \\
\hline Range & $213.4-1280.2$ & $574-2755.2$ & \\
\hline \multicolumn{4}{|l|}{\begin{tabular}{|l|} 
Engraftment Kinetics \\
\end{tabular}} \\
\hline $\begin{array}{l}\text { - Median time to neutrophil engraftment } \\
\text { (days) }\end{array}$ & 11 & 11 & 0.719 \\
\hline Range & $9-16$ & $9-17$ & \\
\hline $\begin{array}{l}\text { - Median time to platelet engraftment } \\
\text { (days) }\end{array}$ & 13 & 11.5 & 0.100 \\
\hline Range & $9-26$ & $8-22$ & \\
\hline
\end{tabular}

Table 2. Study Outcomes. * 2 patients in the Nivestim arm had both back pain and bone pain. ${ }^{\dagger}$ Drug acquisition cost was calculated based on the drug cost at the time of the study.

Safety. Safety profile of the two G-CSFs appeared to be similar. Incidence and severity of adverse events were comparable between Nivestim and Neupogen. However, a significantly higher proportion of patients in the Neupogen arm had missing safety data, as shown in Table 2 . Headache, back pain, and bone pain were among the most commonly reported adverse events in both arms. The adverse events were mainly mild to moderate in severity, with none of the patients experiencing grade 3 and above events. There were also no cases of mortality.

Mobilization and apheresis outcomes. The median number of CD34+ cells mobilized using Nivestim was higher at $7.56 \times 10^{6}$ per kilogram body weight (range; 0 to 45.9 ) as compared to $6.81 \times 10^{6}$ per kilogram body weight (range; 0.2 to 40.63 ) using Neupogen. However, this difference did not reach statistical significance. As shown in Table 2, the median number of apheresis days required was similar between the two groups; while the median length of hospitalization required for mobilization was significantly shorter for the Nivestim arm $(\mathrm{p}=0.035)$. Two and six patients from the Nivestim and the Neupogen arm, respectively, had prolonged hospitalization beyond 30 days. Majority of the prolonged hospitalization cases were associated with severe sepsis, including an isolated case in the Nivestim arm where intensive care admission was required.

Drug acquisition cost. The use of Nivestim for mobilization resulted in a significantly lower drug acquisition cost as compared to Neupogen, $\$ 533.4$ vs $\$ 1261.9$ ( $\mathrm{p}<0.0001$ ), as indicated in Table 2. Of note, the median duration of G-CSF use per mobilization was lower when using Nivestim (9 days) as compared to that of Neupogen (10 days).

Engraftment outcomes. As shown in Table 2, engraftment kinetics after subsequent autoSCT for both neutrophils and platelets were similar between the two groups. 


\begin{tabular}{|c|c|c|}
\hline & $\begin{array}{l}\text { Nivestim } \\
(\mathrm{N}=65)\end{array}$ & $\begin{array}{l}\text { Neupogen } \\
(\mathrm{N}=66)\end{array}$ \\
\hline \multicolumn{3}{|l|}{ Chemo-mobilization regimen } \\
\hline - Cyclophosphamide/vinorelbine, $\mathrm{n}$ & 27 & 22 \\
\hline Mobilization success, $n(\%)$ & $26(96.3)$ & $21(95.5)$ \\
\hline - High dose cyclophosphamide, $n$ & 6 & 25 \\
\hline Mobilization success, $n(\%)$ & $6(100)$ & $25(100)$ \\
\hline - Others, $\mathrm{n}$ & 32 & 19 \\
\hline Mobilization success, $n(\%)$ & $31(96.9)$ & $18(94.7)$ \\
\hline \multicolumn{3}{|l|}{ Lines of treatment } \\
\hline$\bullet 1, \mathrm{n}$ & 39 & 43 \\
\hline Mobilization success, $n(\%)$ & $37(94.9)$ & $43(100)$ \\
\hline - $>1$ line, $n$ & 26 & 23 \\
\hline Mobilization success, $n(\%)$ & $26(100)$ & $21(91.3)$ \\
\hline
\end{tabular}

Table 3. Mobilization Success Sub-Group Analysis. *All p-value were $>0.05$.

\section{Discussion}

Successful mobilization of sufficient PBSCs is of paramount importance in an autoSCT. It has primarily replaced stem cell harvest from the bone marrow due to ease of collection, avoidance of risk of general anaesthesia, as well as more rapid recovery of blood counts.

Several existing publications have demonstrated comparable safety and efficacy of biosimilar G-CSF with the originator in the context of PBSC mobilization for autoSCT. However, the bulk of these studies were not powered with sample size calculation, descriptive in nature, and mostly involved biosimilar of a different brand. This appropriately powered study, with the largest sample size to our knowledge so far, contributes to the growing pool of evidence supporting the use of biosimilar G-CSF.

Our data demonstrated comparable mobilization success rates between Nivestim (96.9\%) and Neupogen (97\%) after chemo-mobilization of PBSCs. These results were in concordance with other studies conducted in similar settings comparing biosimilar with originator G-CSF in chemo-mobilization.

In a retrospective study by Pham et al. ${ }^{18}$ in 98 multiple myeloma patients, a higher proportion of patients achieved mobilization success with the use of Nivestim (85\%) as compared to Neupogen (81.5\%), but no statistical significance $(p=0.78)$ was found. Though the same biosimilar was used, it is noteworthy that this study had a smaller sample size, and the patients included were less heavily pre-treated with only one line of induction therapy prior to mobilization.

In a study by Lefrère et al. ${ }^{19}$ in France, where the efficacy of biosimilar Zarzio was compared to Neupogen for chemo-mobilization in a population consisting of both multiple myeloma and lymphoma patients, it was found that the median CD34+ cells collected was comparable between both arms $(p=0.26)$, with a slightly higher number of cells collected from Zarzio $\left(5.5 \times 10^{6}\right)$ as compared to Neupogen $\left(4.49 \times 10^{6}\right)$. Another single-centred study conducted in Hungary by Reményi et al. ${ }^{16}$ also demonstrated a mobilization success rate of $91 \%$ for biosimilar Zarzio, comparable with published data for Neupogen.

There were no remarkable findings in terms of safety profile of Nivestim. Majority of the adverse events reported were expected and commonly encountered for G-CSF, and were mild to moderate in severity ${ }^{20}$. The commonly documented adverse events from the current study seemed comparable to other similar studies including the one by Lefrère et al., where 14 cases of bone pain and/or headache were noted among the 40 patients who received Zarzio, but no statistical analysis was performed ${ }^{19}$.

In terms of the apheresis process, the use of biosimilar Nivestim did not result in increased G-CSF injections or apheresis sessions required as compared to Neupogen.

Engraftment kinetics after reinfusion of PBSCs upon completion of high dose chemotherapy in autoSCT was included in the analysis as a surrogate marker of quality of the harvested PBSCs. The current study did not show any difference in time to engraftment between the Nivestim and Neupogen arms. From this finding, it appeared that the use of Nivestim did not affect quality of PBSCs mobilized, translating to comparable efficacy in stem cell mobilization.

While the current study looked into the drug acquisition cost of Neupogen and Nivestim for the mobilization process of an autologous stem cell transplant, it was not known how the use of biosimilars affected other indirect costs such as length and cost of hospitalization, number of injections and apheresis sessions required, and the apheresis cost incurred. A study by Severson C. also concluded that biosimilar was more affordable which improved the access of G-CSF for use in stem cell transplant as per recommendation in guidelines ${ }^{21}$. Hence, to determine the true pharmacoeconomic outcome, a cost-minimization study may be considered.

Limitations. The main limitation of this study was the retrospective nature, and resultant inability to match patients in the two arms based on patient demographics and chemo-mobilization regimen while maintaining the calculated sample size. In addition, data on adverse effects collected was dependent on the accuracy, consistency, and completeness of documentation in the clinical progress notes. There was also a high incidence of missing data on adverse events especially in the Neupogen arm due to unavailability of clinical progress notes. Lastly, analysis of both drug acquisition cost and other indirect costs would have provided a more comprehensive and meaningful pharmacoeconomic evaluation on the use of biosimilars in this setting. 


\section{Conclusion}

In conclusion, Nivestim was found to be safe and non-inferior to Neupogen in the chemo-mobilization of stem cells for autologous stem cell transplant, yet at a lower drug cost and a potentially shorter length of hospitalization.

Received: 18 July 2019; Accepted: 4 November 2019;

Published online: 27 December 2019

\section{References}

1. Gratwohl, A. et al. Hematopoetic stem cell transplantation for solid tumors in Europe. Ann Oncol. 15(4), 653-60 (2004).

2. DiPiro, J. T. Pharmacotherapy: a pathophysiologic approach. 8th ed. New York: McGraw-Hill Medical; xxxii, 2668 (2011).

3. Multiple Myeloma. NCCN Clinical Practice Guidelines in Oncology Version 2 (2017).

4. Dhakal, B. et al. Autologous Transplantation for Newly Diagnosed Multiple Myeloma in the Era of Novel Agent Induction: A Systematic Review and Meta-analysis. JAMA Oncol. 4(3), 343-50 (2018).

5. Non-Hodgkin's Lymphoma. NCCN Clinical Practice Guidelines in Oncology. Version 2 (2018).

6. Hodgkin Lymphoma. NCCN Clinical Practice Guidelines in Oncology. Version 2 (2018).

7. Philip, T. et al. Autologous bone marrow transplantation as compared with salvage chemotherapy in relapses of chemotherapysensitive non-Hodgkin's lymphoma. N Engl J Med. 333(23), 1540-5 (1995).

8. Weise, M. et al. Biosimilars: what clinicians should know. Blood. 120(26), 5111-7 (2012).

9. Engert, A. et al. Incidence of febrile neutropenia and myelotoxicity of chemotherapy: a meta-analysis of biosimilar G-CSF studies in breast cancer, lung cancer, and non-Hodgkin's lymphoma. Onkologie. 32(10), 599-604 (2009).

10. European Medicines Agency. Nivestim. [cited 201613 February] Available from: http://www.ema.europa.eu/ema/index. jsp?curl=pages/medicines/human/medicines/001142/human_med_001344.jsp\&mid=WC0b01ac058001d124.

11. Abraham, I., Tharmarajah, S. \& MacDonald, K. Clinical safety of biosimilar recombinant human granulocyte colony-stimulating factors. Expert Opin Drug Saf. 12(2), 235-46 (2013).

12. Cesaro, S. et al. Biosimilar granulocyte-colony-stimulating factor for mobilization of autologous peripheral blood stem cells in pediatric hematology-oncology patients. Transfusion. 55(2), 246-52 (2015).

13. Waller, C. F., Bronchud, M., Mair, S. \& Challand, R. Comparison of the pharmacodynamic profiles of a biosimilar filgrastim and Amgen filgrastim: results from a randomized, phase I trial. Ann Hematol. 89(10), 971-8 (2010).

14. Waller, C. F., Bronchud, M., Mair, S. \& Challand, R. Pharmacokinetic profiles of a biosimilar filgrastim and Amgen filgrastim: results from a randomized, phase I trial. Ann Hematol. 89(9), 927-33 (2010).

15. Hospira History. [cited 201613 February] Available from: http://www.hospira.com/en/about_hospira/our_history.

16. Reményi, P. et al. Peripheral blood stem cell mobilization and engraftment after autologous stem cell transplantation with biosimilar rhG-CSF. Adv Ther. 31(4), 451-60 (2014).

17. Bassi, S. et al. Safety and efficacy of granulocyte colony-stimulating factor biosimilars in engraftment after autologous stem cell transplantation for haematological malignancies: a 4-year, single institute experience with different conditioning regimens. Blood Transfus. 13(3), 478-83 (2015).

18. Pham, T. et al. Comparison of biosimilar filgrastim with originator filgrastim for peripheral blood stem cell mobilization and engraftment in patients with multiple myeloma undergoing autologous stem cell transplantation. Transfusion. 55(11), 2709-13 (2015).

19. Lefrère, F. et al. First experience of autologous peripheral blood stem cell mobilization with biosimilar granulocyte colonystimulating factor. Adv Ther. 28(4), 304-10 (2011).

20. Amgen Manufacturing Limited. Neupogen (Filgrastim) package insert. Puerto Rico, United States (Nov 2015).

21. Severson, C. C. The role of biosimilar granulocyte colony stimulating factor (GCSF) Zarzio for progenitor cell mobilization and the treatment of therapy-induced neutropenia in adult hematopoietic stem cell transplantation. Can Oncol Nurs J. 25(4), 443-54 (2015).

\section{Acknowledgements}

This publication was supported by the Publication Fund from SingHealth Group Allied Health.

\section{Author contributions}

C.C. wrote the main manuscript text and prepared all the figures. N.H.Y. oversaw the project and assisted in the writing of the manuscript.

\section{Competing interests}

The authors declare no competing interests.

\section{Additional information}

Correspondence and requests for materials should be addressed to C.C.

Reprints and permissions information is available at www.nature.com/reprints.

Publisher's note Springer Nature remains neutral with regard to jurisdictional claims in published maps and institutional affiliations.

(c) (i) Open Access This article is licensed under a Creative Commons Attribution 4.0 International cc) License, which permits use, sharing, adaptation, distribution and reproduction in any medium or format, as long as you give appropriate credit to the original author(s) and the source, provide a link to the Creative Commons license, and indicate if changes were made. The images or other third party material in this article are included in the article's Creative Commons license, unless indicated otherwise in a credit line to the material. If material is not included in the article's Creative Commons license and your intended use is not permitted by statutory regulation or exceeds the permitted use, you will need to obtain permission directly from the copyright holder. To view a copy of this license, visit http://creativecommons.org/licenses/by/4.0/.

(C) The Author(s) 2019 